\title{
A IMPORTÂNCIA DO VÍNCULO ETNOGRÁFICO PARA A COMPREENSÃO E ANÁLISE DOS DADOS: PESQUISA COM CORONARIOPATAS EM UM HOSPITAL PÚBLICO NO RIO DE JANEIRO
}

\author{
MAYARA CASSIMIRA DE SOUZA \\ JAQUELINE TERESINHA FERREIRA
}

\begin{abstract}
RESUMO
Esse estudo pretende relatar uma perspectiva reflexiva da construção do vínculo entre pesquisador e interlocutores no universo dos coronariopatas internados em um hospital público do Rio de Janeiro, suscitando os desafios de seu trajeto, percepção e vivência. Os preceitos metodológicos fundamentam-se na pesquisa qualitativa com método etnográfico, utilizando como técnicas a observação participante e entrevistas etnográficas. 0 período de sua realização data entre setembro de 2016 a fevereiro de 2017. Foram entrevistados 16 pacientes adultos (8 mulheres e 8 homens), com 0 intuito de perceber as interações dos pacientes coronariopatas na internação hospitalar. Essa vivencia possibilitou a importância do exercício de reflexividade por parte do pesquisador durante todo o trabalho de campo de forma a compreender como as relações entre esse e os seus interlocutores e dos mesmos entre si, são parte integrante da interpretação dos dados para 0 alcance de novas e profícuas compreensões no campo da saúde.
\end{abstract}

\author{
PALAVRAS-CHAVES \\ Vínculo etnográfico; Coronariopatas; Emoções; Reflexividade.
}

\section{THE IMPORTANCE OF THE ETHNOGRAPHIC LINK FOR DATA UNDERSTANDING AND ANALYSIS: CORONARIOPATHY RESEARCH IN A PUBLIC HOSPITAL IN RIO DE JANEIRO}

\begin{abstract}
This study aims to report a reflective perspective of the construction of the bond between researcher and interlocutors in the universe of coronary disease patients admitted to a public hospital in Rio de Janeiro, raising the challenges of their path, perception and experience. The methodological precepts are based on qualitative research with ethnographic method, using participant observation and ethnographic interviews as techniques. The period of its performance dates from September 2016 to February 2017. Sixteen adult patients (8 women and $8 \mathrm{men}$ ) were interviewed in order to understand the interactions of coronary artery disease patients in hospitalization. This experience made possible the importance of the reflexivity exercise by the researcher throughout the field work in order to understand how the relations between him and his interlocutors and each other, are an integral part of the interpretation of the data to reach new ones. and fruitful understanding in the field of health.
\end{abstract}

\section{KEYWORDS}

Ethnographic bond; Coronary artery disease; Emotions; Reflexivity. 


\title{
L'IMPORTANCE DU LIEN ETHNOGRAPHIQUE POUR LA COMPRÉHENSION ET L'ANALYSE DE DONNÉES: RECHERCHE SUR LA CORONARIOPATHIE DANS UN HÔPITAL PUBLIC DE RIO DE JANEIRO
}

\begin{abstract}
RÉSUMÉ
Cette étude vise à présenter une perspective réflexive de la construction du lien entre le chercheur et ses interlocuteurs dans l'univers des patients coronariens admis dans un hôpital public de Rio de Janeiro, en relevant les défis de leur parcours, leur perception et leur expérience. Les préceptes méthodologiques sont basés sur une recherche qualitative avec une méthode ethnographique, utilisant comme technique l'observation participante et les entretiens ethnographiques. La période de sa performance va de septembre 2016 à février 2017. Seize patients adultes (8 femmes et 8 hommes) ont été interrogés afin de comprendre les interactions des patients atteints de coronaropathie lors d'une hospitalisation. Cette expérience a rendu possible l'importance de l'exercice de réflexivité effectué par le chercheur tout au long du travail sur le terrain afin de comprendre comment les relations entre lui et ses interlocuteurs et entre eux font partie intégrante de l'interprétation des données afin d'en atteindre de nouvelles. et compréhension fructueuse dans le domaine de la santé.
\end{abstract}

\section{MOTS-CLÉS}

Lien ethnographique; Maladie coronarienne; Les émotions; Réflexivité.

\section{LA IMPORTANCIA DEL ENLACE ETNOGRÁFICO PARA LA ENTENDIMIENTO Y ANÁLISIS DE DATOS: INVESTIGACIÓN CORONARIOPATHY EN UN HOSPITAL PÚBLICO EN RÍO DE JANEIRO}

\section{RESUMEN}

Este estudio tiene como objetivo informar una perspectiva reflexiva de la construcción del vínculo entre el investigador y los interlocutores en el universo de pacientes con enfermedad coronaria ingresados en un hospital público en Río de Janeiro, planteando los desafíos de su camino, percepción y experiencia. Los preceptos metodológicos se basan en la investigación cualitativa con el método etnográfico, utilizando la observación participante y las entrevistas etnográficas como técnicas. El período de su desempeño data de septiembre de 2016 a febrero de 2017. Dieciséis pacientes adultos (8 mujeres y 8 hombres) fueron entrevistados para comprender las interacciones de los pacientes con enfermedad de las arterias coronarias en la hospitalización. Esta experiencia hizo posible la importancia del ejercicio de reflexividad del investigador a lo largo del trabajo de campo para comprender cómo las relaciones entre él y sus interlocutores y entre sí, son una parte integral de la interpretación de los datos para llegar a otros nuevos. y comprensión fructífera en el campo de la salud.

\section{PALABRAS CLAVE}

Vínculo etnográfico; Enfermedad de la arteria coronaria; Emociones; Reflexividad. 


\section{INTRODUÇÃO}

A área das Ciências Sociais em Saúde consolida-se enquanto uma área de conhecimento revelando um conjunto de características que merecem destaque ao permitir uma compreensão mais ampla e profunda dos fenômenos estudados (KNAUTH; LEAL, 2014). Nesse sentido, Gomes e Silveira (2012, p. 164), nos ensinam que: "Em terrenos qualitativos, para empreender uma pesquisa precisamos articular nossas visões de mundo às teorias que nos informam, assim como expor as racionalidades que the são pertinentes". Рara isso a abordagem etnográfica possibilita olhar de perto e de dentro, diferente de um outro olhar caracterizado como sendo de longe e de fora e nos traz a homogeneização e o isolamento da vida nesses contextos (MAGNANI, 2002). Nesta perspectiva, a etnografia é uma experiência interpretativa que faz com que o pesquisado com com bastante insegurança, perceba 'com que', ou 'por meios de que', ou 'através de que' (ou seja lá qual for a expressão) os outros percebem" (GEERTZ, 1989, p. 89). É a chamada reflexividade que Guber chama de a relação íntima entre a compreensão e a expressão da dita compreensão (GUBER, 2011).

Peirano (1995) salienta que não há possibilidade de ensinar a desenvolver pesquisa de campo como se ensina em outras abordagens metodológicas. Isso se deve a forma como o pesquisador se insere no campo e as relações que estabelece dentro do contexto vivido. Essa forma de estar do pesquisador é distinta do que estamos habituados, pois, sua biografia se liga diretamente a construção da pesquisa, a escolha do objeto investigado, ao enfoque teórico abordado, do contexto histórico mais amplo, das relações que se estabelecem entre o pesquisador e o campo de pesquisa, além dos imprevistos que fazem parte do pesquisar. A autora denomina o pesquisador como um "pesquisador em relação" e destaca o seu processo reflexivo sobre as suas impressões.

As tomadas de decisões acadêmicas não sucedem de modo aleatório, são reflexos do caminho percorrido pelo pesquisador, de sua construção histórica, dos significados que permeiam e constituem sua trajetória. Traduzem suas perspectivas e abrem horizontes para compreensões profícuas inerentes a seu campo de estudo. Assim, nossas experiências desenham o modo pelo qual construímos um olhar. Abrir-se para o campo é crucial, perceber o que ele "pede", "mostra", "revela" não significa perder o rumo, ficar sem direção, mas permitir-se enxergar o novo, perceber novas possibilidades de conhecimento do objeto de pesquisa. Quando isso ocorre o próprio campo nos conduz a caminhos antes não visualizados, abrindo novos horizontes, encaminhando procedimentos diversificados e mais abrangentes antes não planejados (DALMOLIN; LOPES; VASCONCELOS, 2002).

A pesquisa é um exercício de sensibilidade para o pesquisador que porta como referência a experiência de "mundos opostos", ao mesmo tempo que busca a "transposição 
dos mundos", num movimento continuo de mudanças (GEERTZ, 1989). Essa sensibilidade nos conduz a reflexões internas que nos leva a repensar nossas próprias lógicas, afetando o sentido dado às coisas, por conseguinte, conduz à redefinição da leitura que fazemos da forma como nos colocamos no mundo. Ao pesquisador é permitido experimentar uma sensibilidade emocional para deixa-se afetar pelos motivos e intenções que permeiam as interações humanas. Isso leva-o a ultrapassar a lógica que que a realidade é mensurável ou visível. Essa proposta pressupõe a interação com o Outro, uma participação nas tramas da vida cotidiana, uma vez que o pesquisador se faz presente ao vivenciar o fluxo dos acontecimentos na vida do Outro (ECKERT; ROCHA, 2008).

O autor Bizerril (2004) ressalta a relevância da dimensão humana da pesquisa ao considerar o caráter entre etnógrafos e seus interlocutores como cruciais na etnografia. Essa relação é denominada por ele como "vínculo etnográfico", baseada na confiança e cooperação com os interlocutores e é indispensável para realizar a pesquisa. O autor afirma a importância da dimensão humana da pesquisa nas relações estabelecidas entre o etnógrafo e seus interlocutores, sem as quais não ocorreria a experiência etnográfica. O universo intersubjetivo do campo dá acesso ao mundo, ao ponto de vista e à experiência de outros sujeitos.

Assim, esse estudo pretende relatar o vínculo etnográfico entre a pesquisadora e seus interlocutores e suscitar os desafios de seu trajeto, percepção e vivência no universo dos coronariopatas internados. Essa pesquisa tem o intuito de buscar os significados atribuídos pelos pacientes a suas práticas corporais perante os desafios da doença coronariana. As interações que aconteceram no trabalho de campo suscitaram insights e compreensões sobre o objeto de estudo, de forma que se objetiva nesse artigo chamar a atenção sobre a importância da construção desse vínculo entre pesquisados e pacientes na forma como são determinantes para a compreensão e interpretação dos dados.

\section{METODOLOGIA}

O presente trabalho fundamentou-se nos preceitos metodológicos da pesquisa qualitativa com um cunho antropológico. O método qualitativo abarca os estudos relacionados à história, aos significados e representações, motivações, crenças, percepções, relações e opiniões a partir das interpretações dos sujeitos mediante suas vivências e nas suas elaborações de pensamentos e sentimentos em relação a essas (MINAYO, 2010). Assim, a prática da pesquisa de campo etnográfica responde a "uma demanda científica de produção de dados de conhecimento antropológico a partir de uma inter-relação entre o(a) pesquisador(a) e o(s) sujeito(s) pesquisados" (ECKERT; ROCHA, 2008). 
Foi delimitado para análise desse estudo o grupo de pacientes do nono andar, os doentes coronarianos, com as seguintes características: pacientes adultos, independente do sexo, que se encontravam no período pré-operatório de cirurgia cardíaca e pós-operatório tardio. Sendo somente entrevistados os pacientes que demonstrarem interesse na participação do estudo e que concordarem com os itens do Termo de consentimento livre esclarecido.

Foram utilizadas duas principais técnicas nessa pesquisa: observação participante e entrevistas etnográficas. A observação e a entrevista são ferramentas eficazes, que permitiram pesquisar o universo escolhido. Destarte, a pesquisa é um trabalho, é um saberfazer (conhecimento prático) do pesquisador. A utilização de técnicas combinadas buscou suprir as lacunas e tornar mais completa a coleta de informações em campo. Assim, foi possivel aprimorar as competências enquanto pesquisador à medida que desenvolveu o trabalho de anotações das observações e transcrições das entrevistas que sucederam (BEAUD; WEBER, 2014).

As entrevistas etnográficas conduzem-nos a percepções que dão acesso ao universo do paciente, sendo assim, uma relação social, construída entre o entrevistador e os participantes (CICOUREL, 1972). É uma estratégia para que o outro diga sobre o que sabe, pensa e o que crê (SPRADLEY, 1979, p.9). No entanto, estabelecer essa relação depende da forma pela qual o entrevistador se insere ao campo e estabelece relações no mesmo.

As entrevistas foram elaboradas com um roteiro prévio, com sequências de questões, para facilitar a abordagem ao entrevistado e assegurar que os pressupostos sejam cobertos na conversa (MINAYO, 2010). Foi elaborado um roteiro de entrevista embasada no referencial teórico da pesquisa apresentada, sendo ambos direcionados aos pacientes no pré-operatório e no pós-operatório, ambos com o objetivo de apreender as significações do paciente nesses dois momentos e sua influência à adesão dos mesmos as práticas corporais.

Nos roteiros de observações ainda foram anotadas as regularidades (hábitos rotineiros) e variações (excepcionais) da vida cotidiana, que poderiam influenciar no modo pelo qual os pacientes vivenciam o processo pré e pós-operatório (VICTORA; KNAUTH; HASSEN; 2000).

O período da realização das entrevistas e acompanhamento da rotina dos pacientes compreendeu os meses de setembro de 2016 a fevereiro de 2017. As observações se direcionaram para a rotina dos pacientes em seus quartos, as movimentações dos mesmos nos corredores e na área de convívio no hall de entrada dos quartos de leitos. Foram espaços pensados inicialmente como favoráveis para observações e diálogos. Estes locais foram ricos em interações entre pacientes, acompanhantes e ocasionalmente profissionais. Todas as entrevistas ocorreram somente com a presença do paciente nos seus leitos. Foram entrevistados dezesseis pacientes adultos, entre eles oito mulheres e oito homens, que se 
encontravam no período pré-operatório de cirurgia cardíaca e pós-operatório. O tempo médio das entrevistas foi de 20 minutos a 50 minutos.

O critério de finalização da pesquisa foi por saturação de dados. A saturação é assim, "o fenômeno pelo qual o pesquisador julga que os últimos documentos, entrevistas ou observações não trazem mais informações suficientemente novas, ou diferentes, para justificar uma ampliação do material empírico" (POUPART et al, 2012).

Рага auxiliar no desenvolvimento dessa técnica, as entrevistas foram gravadas mediante autorização dos entrevistados, o que facilitou a condução da entrevista, uma vez que a gravação capta na íntegra e em todas as dimensões as palavras do entrevistado, condicionando a qualidade da escuta desses e favorecendo uma análise profunda da mesma (BEAUD; WEBER, 2014). Posteriormente, as gravações foram cuidadosamente transcritas para análises e interpretações.

Sobre o perfil dos pacientes, a maior parte dos observados estava entre 59 e 75 anos (salvo exceções de 59 anos) e se depararam com o problema cardíaco em fase aguda. Estes residem em diferentes regiões da capital do Rio de Janeiro e de diversas cidades do Estado. Quanto ao nível de escolaridade dos pacientes, a maioria estudou até o primário, sendo que dois apenas chegaram ao ensino superior e três eram analfabetos. O grau de escolaridade foi determinado pelo acesso às escolas, interferências de localidades, condições financeiras e valores familiares. A maior parte declara não ter tido educação física escolar. Sobre suas ocupações profissionais, a maior parte dos homens entrevistados já haviam se aposentado, mas continuaram a trabalhar até o acometimento da doença. Quanto às mulheres, essas se ocuparam com afazeres domésticos em seu próprio lar ou prestaram serviços a outros lares.

O projeto seguiu os preceitos éticos da resolução CNS n 466/2012, sendo submetido e aprovado pelo Comitê de Ética de Pesquisa (CEP) do Instituto de Estudos em Saúde Coletiva da Universidade Federal do Rio de Janeiro sob parecer número 1.863.965.

\section{A INSERÇÃO E FAMILIARIZAÇÃO COM O CAMPO}

As inserções iniciais no universo de pesquisa são momentos que devem estar norteados por um olhar atento ao contexto e a tudo que perpassa o local observado. Com isso, é possível aproximar das pessoas, dos grupos, bem como da instituição almejada, conquistando a concordância de estar presente para vir a observar as práticas sociais naquele espaço (ECKERT; ROCHA, 2008).

O hospital é referência do Ministério da Saúde no tratamento de alta complexidade em doenças cardíacas. Atua há mais de 40 anos com destaque em procedimentos hemodinâmicos, cirurgias cardíacas de alta complexidade. O Instituto dispõe de 165 leitos, 
sendo 60 de UTI, com 4 mil internações anuais, 1200 cirurgias e 50 mil consultas médicas. O nono andar, delimitado para as internações de coronariopatas foi o lugar eleito para a pesquisa. Nos corredores concentram-se os quartos com leitos, formando uma divisão por quadrante, sendo que cada quadrado possui dois quartos com portas divisórias e um banheiro no centro. Ao todo são 16 leitos por corredor. Na entrada dos leitos tem um quadro de identificação do paciente com seu nome, data de nascimento, data de entrada, problema e médico responsável. Os quartos recebem os pacientes à espera de cirurgia, pós-cirúrgicos, e de reinternações por intercorrências. Há ainda uma sala de enfermagem, uma sala médica, uma farmácia, uma sala de jogos e um hall de entrada com bancos de apoio.

\section{HIERARQUIAS, ESPAÇOS, OBJETOS E ROTINAS: SOCIABILIDADES EM JOGO}

Segundo Magnani (2009) é preciso se nortear pela imprevisibilidade destacada em relação a "experiência etnográfica". Para além das primeiras impressões no contato com o tema e o campo desconhecido, é no caminhar da pesquisa que as experiências nesse se tornam reveladoras (MAGNANI, 2009). Por isso, procurei estar aberta e atenta aos aspectos próprios desse cenário. Assim, segundo Malinowski (1978) o etnógrafo fica à espreita de fatos significativos percebidos e revelados pelo campo.

Nesse ambiente sempre existia uma enfermeira chefe ou de plantão, demais enfermeiros e técnicos de enfermagem. Tendo em vista que as interações são um ponto de extrema relevância e condição para pesquisa, o encontro com as pessoas não pode se dar de modo fortuito, senão por uma relação prolongada no fluxo do tempo e na pluralidade dos espaços sociais, para então, participar das rotinas dos grupos. Assim, as primeiras visitas na instituição hospitalar foram exploratórias e com o acompanhamento de enfermeiras. Inicialmente, me dirigi aos postinhos, me apresentei às enfermeiras chefes e avisei as que diariamente estaria ali, assim como anunciaria minha entrada e saída do local. As enfermeiras foram as primeiras pessoas que procurei interagir no campo (ECKERT; ROCHA, 2008). Essa relação foi imprescindivel para fluidez da pesquisa, conforme já referido. No diálogo com elas foi possível identificar os melhores horários para as entrevistas, como os de maior movimentação, de maior cautela e acima de tudo compreender a rotina dos pacientes para que minha presença não interferisse no quadro clínico deles. Como refere Favret-Saada (2005), a imersão no cenário escolhido pressupõe acionar estratégias de inserção e de negociação entre pesquisador e interlocutores, uma vez que, a afetação é mútua independentemente do método envolvido.

Quanto aos médicos eu cruzava esporadicamente com eles. Cada médico cuidava de determinados pacientes e os visitava pela manhã ou tarde. Quando estava nos quartos e o médico passava para ver os pacientes, eu algumas vezes permanecia no leito outras vezes 
saia, sempre negociando isso com os mesmos. Com isso, presenciei algumas explicações médicas, o diálogo desses e inclusive algumas altas hospitalares. Os técnicos de enfermagem quando tinham que fazer procedimentos nos pacientes (verificar temperatura ou aplicar medicamentos) entravam nos leitos educadamente, pediam licença e sinalizavam para que permanecesse no leito, olhavam para o paciente, comunicavam o resultado e se despediam.

É notório a relação hierárquica na convivência entre profissionais e pacientes, e como isso afetou a minha presença nesse local. As enfermeiras eram as "guardiãs" dos corredores, sempre preocupadas com a ordem e segurança, com isso, sem o consentimento dessas seria inviável minha circulação. Os técnicos se portavam afim de não atrapalhar o fluxo das rotinas, inclusive os momentos de diálogos que tinha com os pacientes. Já os médicos tinham uma presença imponente e com a chegada deles no leito, havia sempre uma certa negociação sobre a minha presença mesmo que não explícita. Isso é, eu necessitava deixar a minha sensibilidade aguçada para decidir sobre a minha presença ou não no quarto conforme as reações e expressões desses profissionais. Isso condiz com os estudos sobre legitimação do campo médico dentro da equipe multiprofissional (ANTUNES, 2007; DIAS, 2007).

Após esta primeira fase houve uma rotina diária de visitas para percepção dos atores sociais, com o auxílio da observação que foi a melhor maneira de perceber seus saberes, práticas sociais e interações, (POUPART et al, 2012; ECKERT; ROCHA, 2008).

Foi perceptível que a sala de enfermagem, no início do corredor de leitos, também funciona como uma barreira de controle, visto que as pessoas externas ao ambiente são imediatamente percebidas necessitando ser identificadas. A maior parte das pessoas já portam identificações estereotipadas que são determinantes das relações que aí se estabelecem. Os pacientes possuem vestimentas brancas, os acompanhantes (permitidos para os pacientes pós-cirúrgicos e para pessoas acima de 64 anos) possuem vestimentas azuis. Para técnicos, enfermeiros e demais funcionários (limpeza, almoxarifado) é obrigatório o uso de uniforme integral (personalizam com crocs e tocas). Médicos nem sempre usam jalecos, mas estão sempre vestidos socialmente (mulheres com sapatos de salto, camisas e camisetes sociais). Com o tempo percebi que as enfermeiras e técnicos de enfermagem fazem uma leitura corporal mesmo das pessoas que não portam identificação e transitam pelos corredores, uma verdadeira interpretação da hexis corporal à la Bourdieu (1962), ou seja, por meio das relações sociais, de uma matriz de práticas corporais constituem códigos carregados de uma miríade de significações e de valores sociais.

Sobre as identidades expostas e rotuladas nesse cenário é importante destacar que elas preconizam uma ordem e hierarquia no ambiente, mas percebi no convívio com os interlocutores, que elas desafiam as relações, mas não são limitadoras dessas. Embora, todos (com exceção os médicos) usam trajes padronizados, os pacientes possuem certa autonomia 
nos seus espaços privativos e vão usufruir desses na tentativa de preservarem suas identidades pessoais, familiares e religiosas. Рara descrever e compreender essas significações descrevo o ambiente e, posteriormente interpreto as interações nesse.

Assim, a minha inserção na rotina com os pacientes foi inicialmente contida. Sentiame deslocada. Precisei observar cautelosamente os fluxos pessoais, as estruturas físicas e estabelecer o mínimo de interação para me situar e adentrar no espaço observado pelo presente estudo. É preciso ter o cuidado dessa inserção de campo. Este trabalho não pode ser de umas horas, alguns dias, umas semanas, apenas finais de semana ou quando sobra tempo dos compromissos do pesquisador. As compreensões no universo imergido vêm do tempo em campo, visto que somente ele é capaz de proporcionar um duplo processo no pesquisador que consiste em conseguir relativizar sua sociedade e conseguir perceber a coerência da cultura do Outro (MAGNANI, 2009).

Assim, a abordagem aos pacientes transcorreu de modo progressivo. A princípio me aproximei dos pacientes que estavam na porta de seus leitos. Geralmente, ficavam olhando o corredor ou batendo papo com o vizinho. Pareceram-me descontraídos naquele momento e foi possível, assim, uma abordagem mais informal. Ao me apresentar, eu explicava que gostaria de conversar sem maiores preocupações e que meu interesse consistia em obter um diálogo com eles. Expunha meus interesses, falava de maneira simples os meus objetivos. $\mathrm{O}$ tom de voz dessas conversas era sempre terno e me sentia muito acolhida por eles, em seus quartos e sempre eles me pediam para sentar e ficar à vontade.

Depois comecei a verificar os leitos com as portas semiabertas e caso os pacientes não estivessem dormindo e ocupados, pedia licença para entrar e me apresentar. Alguns se levantavam e sentavam para conversar, outros saiam das poltronas e outros continuavam deitados e prosseguiam as entrevistas dessa maneira.

Posteriormente, quando conversava com algum paciente no corredor e surgia uma oportunidade, convidava-o para uma entrevista. Os pacientes ao transitarem pelo corredor geralmente se dirigiam a "pracinha" (bancos no hall de entrada), ou iam visitar um colega de quarto, o que era muito apreciado por eles estas "escapadas" do leito de paciente. Somente depois de conversamos aleatoriamente e, no decorrer da conversa, percebia que estavam receptivos para conversar sobre o tema desse trabalho. Aí voltávamos ao quarto e dávamos continuidade a conversa, na perspectiva da temática ora abordada.

A pracinha era uma estratégia de autonomia pelos pacientes. O hall de entrada dos corredores que possuía bancos, foi um lugar singular, delimitado e nomeado pelos próprios pacientes como "pracinha". Nesse local escolhido coletivamente para convívio eles interagem compartilhando dores, angústias, tristezas e quase sempre o otimismo da volta para casa. 0 objetivo de ir a "pracinha" é dar uma volta, sair do leito, ver e conhecer outros ou quem sabe "semelhantes". 
Foi o último espaço que me inseri, pois não intencionalmente, restringiam aquele espaço "aos deles". Ali os funcionários não se sentavam e, às vezes, quando alguém à espera de informação sentava, logo percebia o estranhamento dos outros através dos seus olhares e, por conseguinte, não permaneciam ali muito tempo. É um espaço eleito, de convívio diário dos pacientes. Somente depois de já estar familiarizada por eles e fazer parte do cenário que fui convidada a acompanhá-los e partilhar com eles esse rico espaço.

Em contrapartida, na pracinha adotada para os encontros entre os pacientes, os outros locais designados pelo hospital para isso não possuíam o mesmo significado e importância para eles. As salas de jogos eram próximas aos quartos, grandes, com janelas amplas, cadeiras em volta, muitos murais com trabalhos manuais, mesa com diversos jogos, caixa com palavras cruzadas, cadernos e livros, uma televisão grande e banners de conscientização sobre hipertensão, diabetes, fumo e etc. Apesar de toda essa estrutura ela não era tão frequentada quanto à "pracinha". Os pacientes diziam que ela era a "sala da terapeuta", mas a terapeuta só permanecia nela em horários determinados, em certos dias da semana quando realizava uma reunião orientando os pacientes e seus acompanhantes sobre os cuidados com o corpo antes e após a cirurgia, como por exemplo: o sentar e levantar das macas, como tossir (abraçar a almofada de coração), melhores formas de tomar banho e deitar-se, entre outras.

Esses espaços de sociabilidade muito ou pouco frequentados pelos pacientes constituíam vínculos emocionais entre esse grupo social. O autor Koury (2010) enfatiza que os vínculos conformam os sentimentos de pertencimento, dignidade e semelhança, e é por meio das trocas materiais e simbólicas que a construção da confiança e da confiabilidade coletiva que se partilha as identidades e significâncias das interações humanas, ou seja, de uma cultura emotiva concreta.

Reconhecer o espaço do paciente foi fundamental para aproximar-se dos seus desenhos cotidianos, de suas percepções e enlace de relações. Assim, seus espaços, suas trajetórias, suas redes sociais compunham o cenário do estudo. Compreender esse processo, que constitui a vida das pessoas, repercute na sua condição de saúde/doença (DAMOLIN, LOPES; VASCONCELOS, 2002).

Devido a isso, procurei ampliar minhas possibilidades de contato com os pacientes nos corredores e com o tempo passei a frequentar a "pracinha". la conversando e acompanhando alguém até lá, e por lá me convidavam a sentar e continuávamos a conversar. Os outros me olhavam, como que identificando minha presença ali, depois entravam na conversa e tudo parecia correr como o habitual. Em certas ocasiões, chegava alguém e me perguntava o que eu era do hospital, visto que não conseguia me identificar e eu, na maioria das vezes, não me identificava nesse momento. 
Em relação aos quartos, observei que estavam sempre limpos, cheirosos e muitos são personalizados. O cheiro vinha de produtos de limpeza, de perfumes dos próprios pacientes. Cada quarto possuía um leito e uma poltrona muito confortável, um armário aberto, ar condicionado com controle, mesa para refeição, janela grande e bem arejada e um botão de emergência ao lado do leito.

No entanto, sempre havia nos quartos objetos personalizados que serviam de referência para o paciente e familiarização com aquele meio. Em geral, grande parte levava televisão, o que era permitido e há sinal para que funcionem. Há televisões antigas, modernas, pequenas e grandes. Dispõem também de objetos religiosos, tais como: bíblias, livros religiosos, guias espíritas, terços, budas, imagens de santos, o que torna a identificação religiosa visível ${ }^{1}$. Os pacientes não se acanham ao falarem de seus objetos, assim como, de suas crenças religiosas. Sempre explicitam o desejo de boas coisas espiritualmente a si mesmas e a quem socializa com eles. Frases típicas e personalizadas, como por exemplo:

"Vai com Deus filha."

"Jesus te guarde!"

"Deus sempre ajuda."

"Temos que evoluir, a vida é assim!"

"Deus sabe de tudo e tem um plano para cada um de nós."

"Eu acredito que vivemos para o outro, tem que vê o outro, é o ciclo da vida."

Os homens possuíam camisas, toalhas e bandeiras de times. Alguns brincavam quanto aos seus times. Era possível interagir de imediato com alguns quando o assunto era futebol. As mulheres possuíam produtos de beleza (cremes, perfumes, pentes). Ressaltavam o cuidado com o corpo e gostavam de receber elogios sobre sua aparência.

Há ainda aqueles que colocavam fotos nas paredes ou possuíam fotos avulsas e álbum de fotografia e faziam questão em mostrar suas famílias para os visitantes e para mim. Também falavam muito com os familiares pelo celular. Cartas familiares e desenhos infantis estavam presentes em alguns quartos. Assim, todos os quartos possuíam objetos pessoais.

Almofadas e travesseiros pessoais preenchem vários leitos, para maior conforto e adaptação. Porém, em todos os quartos tem uma almofada vermelha em formato de coração, de material resistente e com aproximadamente 30 centímetros. Ela é ofertada pelo hospital a cada paciente, demonstrando que a instituição se utiliza de um símbolo universal para proporcionar maior conforto ao paciente, tanto emocional como físico, uma vez que serve para apoio de peito quando há dores e tosses sentidas pelo paciente. Quando o paciente sentir dor ou tossir deve abraçar o coração, apertá-lo e soltá-lo após amenização da tosse e dor. Quando perguntava sobre a almofada aos pacientes ou quando eles expressavam espontaneamente sobre a mesma, diziam:

\footnotetext{
${ }^{1}$ Nesse aspecto, o hospital se diferencia muito das Instituições totais de Erwing Goffman (1961) onde não são permitidos objetos pessoais e há todo um "trabalho" para a perda de identidade dos doentes.
} 


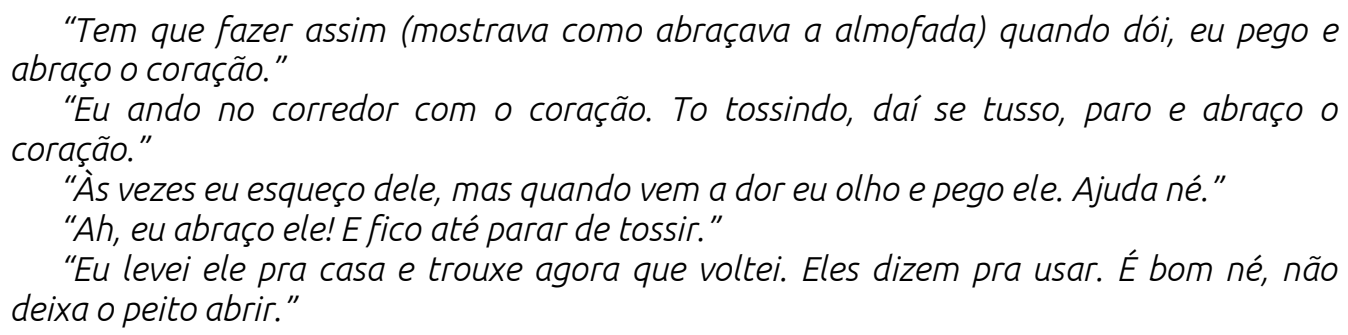

A impressão que se tem é que no momento de sofrimento é preciso "pegar" o coração e não o soltar. Esse objeto conota o próprio coração do paciente, como uma forma de segurá-lo e cuidar dele. Esse simples gesto proporcionou-me como pesquisadora, o exercício do olhar (ver) e do escutar (ouvir) desloca o pesquisador do seu lugar (cultura) para situar-se no interior do fenômeno por ela observado (ECKERT; ROCHA, 2008). A participação efetiva nas formas de sociabilidade nos leva a inserir-se no universo do paciente e faz com que a apreensão do campo ocorra, por meio de uma percepção intensa, uma integralidade dos sentidos do pesquisador. A descrição etnográfica não se limita à percepção visual dos fenômenos, pois a "visibilidade" do pesquisador é além do que se vê, é olfativa, tátil, gustativa e auditiva (LAPLANTINE, 2004). '

Esses objetos eram um meio para construir a comunicação nesse contexto, pois eles dialogavam com os outros internados, com o staff e visitantes. Eles expressavam seus sentimentos e expectativas. Eles proporcionavam um maior vínculo com a possibilidade de profundos diálogos sobre suas vidas, interesses e sociabilidades. Eles também eram uma forma de conexão com o mundo a que pertenciam e desejavam retornar.

Em relação ao cumprimento da rotina definida nos leitos havia um desconforto explicito pelos pacientes e seus familiares. Por exemplo, as refeições eram servidas pontualmente com um tempo limite para permanecer no quarto. Isso os obrigava a comê-las mesmo sem fome ou apetite. Com isso, havia muitas reclamações sobre a permanência do alimento por mais tempo no local. Alguns conseguiam negociar isso (com menor frequência), os demais reclamavam, mas continuavam com as rotinas inflexíveis. Outros momentos muitos discutidos são sobre os horários de visitas e permanência de familiares que acompanhe os pacientes com idade inferior a 65 anos. De fato, esse nunca supria as demandas sentimentais dos internados.

Embora, esse ambiente hospitalar fosse enquadrado, ordenado e estabelecido sobre regras pontuais, os pacientes por meio da expressão de seus sentimentos buscavam manterem suas singularidades - uma forma de preservarem suas identidades - enquanto superavam a realização da cirurgia, e esperavam retornar a seu dia-a-dia habitual.

Essas estratégias de manter seus objetos personalizados ou hábitos pessoais buscavam uma gerenciar uma certa autonomia e necessidade de manter a sua singularidade 
em um ambiente que busca homogeneizar e despersonalizar os indivíduos como o hospital (GOFFMAN, 1961).

Assim, imergir no campo de pesquisa nos remete a permissão do outro (paciente) em dispor seu sistema de crenças e de prática. Tal relação se estabelece por intermédio da confiança que o pesquisador adquire no outro e de seu grupo que, por sua vez, passam a aceitar e se deixar observar pelo pesquisador que dá continuidade à sua pesquisa inserida nesse cotidiano (FOOTE-WHYTE, 2005).

\section{A CONSTRUÇÃO DO VÍNCULO ETNOGRÁFICO: O LUGAR DOS AFETOS E EMOÇÕES}

Apresentava-me como pesquisadora, porém, ressaltava meu interesse em compreendê-los. Percebia que encaravam aquele momento como uma ajuda para mim e eles simplificavam me vendo como estudante. Minhas vestimentas eram simples e básicas; não colocava nenhum acessório e objeto de identificação, mas, por vezes, tinha uma pasta em mãos. Eles me diziam que poderiam conversar e me ajudar. Havia pedidos ao longo da conversa para esclarecer perguntas para que eles pudessem entender e alguns se mostravam muito interessados em falar sobre suas vidas.

Ao final de algumas entrevistas, diziam:

"só isso filha. Você não precisa de mais nada".

"pode perguntar mais se quiser, depois volta ai".

"ta bom assim? Deu para ajudar né!".

"ta bom, se precisar de mais alguma coisa depois pode voltar".

A receptividade e até alegria de alguns foi contagiante com a minha presença. Desocupavam a poltrona quando possível, me pediam para remover objetos de lá para sentar, ou puxar cadeira extra para sentar, até mesmo me ofereciam suas refeições. Escutava sempre frases positivas e eles pediam que retornasse sempre. Era notável os sentimentos de solidariedade dos pacientes ao compartilharem seus espaços e dialogar nas entrevistas etnográficas, ou seja, a aceitação para integrar a pesquisa passa pelo acolhimento ao pesquisador. Isso vai ao encontro do que Favret-Saada (2005) denomina de "afetamentos", ou seja, as relações estabelecidas no campo entre pesquisador e interlocutores é um fluxo contínuo de aprendizagem e trocas entre ambos; e perpassa sua sensibilidade a partir de sua própria relação com o campo.

Em relação ao desenvolvimento das entrevistas, foram mais objetivas no começo, uma vez que me encontrava ainda muita presa aos objetivos do roteiro pré-estabelecido. Posteriormente, com mais segurança e familiarizada com a rotina de perguntas, fui desapegando do papel e estabelecendo mapas mentais que me permitiam fluir com a conversa e relembrar pontos dos diálogos a serem explorados. Destarte, no contexto da 
situação se evidencia a comunicação, que engloba todos os sentidos - o olfato, a visão, a percepção espacial e o tato (MALINOWSKI, 1978). Por isso, mais que procurar uma ordem de diálogo é interagir e ser receptível as possibilidades de comunicação.

Assim, embora houvesse um roteiro pré-estabelecido outras dimensões de sentidos foram sendo percebidas nas relações com os pacientes. Рara isso, me fundamentei no conceito de entrevista etnográfica que Guber (2011) expõe sobre o quão importante essa entrevista para descobrir novas perguntas no fluxo da vida cotidiana do participante, ou seja, a partir da identificação de seus sentidos e percepções do seu contexto torna possível construir novas perguntas no desenrolar do diálogo. Isso só foi possível com certo tempo de convívio com os pacientes, pois no início a falta de experiência no modo de falar e me expressar com o paciente me causava insegurança e demasiada cautela. Posteriormente fui percebendo que não havia um modo pré-estabelecido para isso, mas que nosso diálogo era uma construção entre dois, na interação.

Em certas ocasiões nos corredores, pracinha e sala de jogos, não perguntava nada aos pacientes, apenas comentava de questões diárias. Muitas vezes só escutava-os conversarem, outras falávamos de diversos assuntos, como por exemplo, do tempo, de política, de saudade e família. Esses momentos informais foram extremamente ricos рага percepção do mundo dos pacientes e para que eu os percebesse para além da doença.

Enquanto pesquisadora foi necessário me aproximar e me afastar várias vezes do contexto inserido. Victora, Knauth e Hassen, (2000) entende que o pesquisador:

\footnotetext{
"....precisa estar ao mesmo tempo próximo e distante do grupo estudado (...). Ele precisa estar próximo do grupo pesquisado e, ao mesmo tempo, dele distanciar-se para não ser excessivamente impregnado pela problemática e pelo ponto de vista do grupo pesquisado" (VICTORA; KNAUTH; HASSEN, 2000, p.55).
}

Depois de certa aproximação às vivências dos pacientes, percebi que busquei me afastar em diversos momentos. Houve dias que não conseguia fazer nenhuma entrevista, ou apenas uma e nunca mais que duas. Algumas histórias e reações dos pacientes eram emocionalmente fortes e cheguei a descontinuar entrevistas. Por exemplo, um paciente que ao relatar sobre a família começou a chorar ou, em outras ocasiões que presenciei relações de acompanhantes desesperados com pacientes. Ficava impregnada de tal modo pelo contexto do paciente que necessitava sair do hospital, respirar e processar o ocorrido. Também em situações como o choro coletivo na pracinha precisei me retirar antes de ficar imersa pelas significações dos pacientes.

Este material foi lido e relido durante o processo da pesquisa para que novas interpretações fossem feitas ou questões sejam aprofundadas. Através dos diários levantouse além de dados pertinentes ao contexto da pesquisa e seus sujeitos, também o movimento da pesquisadora, movimento este destacado no presente artigo. 
É importante perceber que a teoria e a prática são inseparáveis na pesquisa, portanto, o fazer etnográfico é perpassado o tempo todo pela teoria. Antes de ir a campo, no decorrer dessa jornada e após essa é necessário informa-se sobre todo o conhecimento produzido sobre a temática e o grupo a ser pesquisado. Na jornada em campo, o olhar do pesquisador e seu escutar deve ser moldado e disciplinado pela teoria. Por conseguinte, após sua jornada de pesquisa, este colocará em ordem os fatos, para traduzi-los e emoldurandolos numa teoria interpretativa (PEIRANO, 2014).

Рara Crapanzano (1985) os discursos estabelecidos são carregados de emoções, assim, toda enunciação contém uma dimensão afetiva. Mesmo que por vezes elas sejam sublinhadas, ignoradas, mascaradas ou negadas nos discursos apresentados. Somado a sensibilidade e subjetividade do pesquisador, as emoções expostas entre esse e os interlocutores compõe as interpretações narradas.

E somente por esse caminho de construções identitárias e a experiência de estar ali é possível aprofundar na interação com os pacientes. Assim, eles traziam espontaneamente na conversa corriqueira detalhes sobre os seus sentimentos. Houve um momento na "pracinha", que um paciente que aguardava cirurgia estava triste e expressava o sofrimento e angústia da espera e em dado momento começou a chorar. Os pacientes sentados (3 pessoas) ao redor começaram também a chorar. Todos esperavam a cirurgia e diziam uns aos outros em poucas e simples palavras "é difícil, é difícil", "tem que aguentar né" balançavam a cabeça e lágrimas eram compartilhadas.

Essa aproximação implica acessar uma comunicação com o Outro para compreendelo, pois "[...] o próprio fato de que aceito ocupar esse lugar e ser afetada por ele abre uma comunicação específica com os nativos: uma comunicação sempre involuntária e desprovida de intencionalidade, e que pode ser verbal ou não" (FAVRET-SAADA, 2005, p.159). Portanto, essas experiências pressupõem uma reflexividade intensa no ato de estranhar e desnaturalizar o Outro e a si mesmo (GOLDMAN, 2003).

Adorno e Castro (1994) ressaltam que perceber as condições de vida nas quais as pessoas se inserem, permite olhar - dar-se a conhecer - o modo como estas se articulam e criam possibilidades de saúde e doença. Este conhecer leva o pesquisador a uma experiência intersubjetiva "que conduz à revisão do sentido dado às coisas, podendo corresponder à necessidade de se situar, de achar um espaço específico na multiplicidade de espaços presente na contemporaneidade fragmentada" (p. 182).

Com isso, no convívio com os pacientes foi explícito que esses se sentiam limitados pela doença, mas não se compreendiam apenas por ela. Eles se reconhecem através dos sentimentos atribuídos e compartilhados com a família e amigos, e diante das possibilidades de manterem suas singularidades nesse ambiente passageiro. 


\section{CONSIDERAÇÕES FINAIS: O VÍNCULO ETNOGRÁFICO E O TORNAR-SE PESQUISADOR}

O desbravar do campo permeia uma construção identitária. Ao me aproximar do método etnográfico preconizei o cuidado de não "engessar", não me "limitar" a modos pelos quais poderia ultrapassar uma descrição linear, ao mesmo tempo em que procurava exercitar um olhar sobre o que era estranho e familiar. A tentativa foi percorrer o caminho sem "cair na mera descrição ou recolha de dados a serem posteriormente trabalhados" deveríamos "delimitar o cenário, identificando marcos, reconhecendo divisas e não apenas anotando equipamentos e estruturas físicas" (MAGNANI, 2000, p. 37).

Bachelard (1996) ressalta que a imersão ao campo deve se nortear pela busca de olhar o outro para conhecê-lo, mas sempre com o cuidado de buscar apreender o local em que se insere e seu universo orientado por questões conceituais aprendidas no estudo das teorias sociais. Assim, busquei perceber minuciosamente esses espaços, as rotinas ali estabelecidas para, posteriormente, perceber como se estabelece as relações e interações no ambiente hospitalar, com o foco sobre como os pacientes constroem estratégias para estar nesse contexto.

Sobre esse contato com os pacientes internados é importante expor que não há uma forma padrão para essa abordagem, embora haja um desconforto e insegurança ao inserir no cenário. Esse contato é uma construção constante e cheia de surpresas no campo etnográfico. Malinowski e Lévi-Strauss ressaltam essas surpresas diante de uma ingenuidade assumida, que é parte integrante da inquietação e do interesse que o etnógrafo experimenta no trabalho de campo. Além do mais, a personalidade do investigador e sua experiência pessoal não são anuladas no trabalho etnográfico, mas são cravadas nos fatos etnográficos que são selecionados e interpretados, assim como, a capacidade do pesquisador de se colocar no lugar do outro (COETZEE, 1999).

Portanto, a teoria é fundamental para direcionar e embasar o olhar e sensibilidade do pesquisador, assim, apesar de ser um encontro singular com o interlocutor, somente com embasamento científico é possível construir um diálogo produtivo (PEIRANO, 1995).

As vivências relatadas, percebidas e vividas remetem ao fato do campo como um espaço que não está dado, mas em construção constante, num intenso movimento que vai tomando sentido e se singularizando na relação com o outro. As relações que se desenvolvem neste é o resultado do que ambos podem em determinado momento doar e perceber, por isso, as possibilidades criadas pelo conjunto (pesquisador e interlocutores) no decorrer da pesquisa, é elemento central em pesquisas dessa natureza e um desafio para o pesquisador. Além do desenvolvimento do ouvir, todos os outros sentidos são requeridos para novas construções simbólicas, pois não é apenas observar ou agir, trata-se de 
estabelecer novas relações. Dalmolin, Lopes e Vasconcelos (2002) salientam e reforçam que o lugar do autor/pesquisador no trabalho etnográfico é uma construção do percurso que deve ser considerada e evidenciada na pesquisa.

A pesquisa realizada, ou melhor, o campo vivenciado foi uma jornada única e imprevisível. Ser pesquisadora nesse espaço exigiu desprendimento e sensibilidade: desprendimento para desnudar-me de minhas lógicas e aproximar-me da lógica do outro; sensibilidade para me deixar afetar não pelo que racionalmente procurava, mas pelo que se revela desde os pequenos detalhes até o que visivelmente se fazia invisível.

Essa experiência num ambiente de internações hospitalares revela o papel crucial nas emoções em qualquer momento da pesquisa, e que mesmo num local tão controlado por rotinas definidas e executadas, por meio da interação com os pacientes, seus objetos e espaços, é possível construir vinculo (relação) com os pacientes e ter acesso ao seu universo e sentimentos.

Portanto, para além da descrição etnográfica desse trabalho evidencia que os pacientes internados possuem percepções positivas de estar no ambiente e esperança de através desse superar seu adoecimento.

Da Matta (1981), enfatiza o sentimento de "estar lá" e do "estar aqui" do pesquisador como um eterno desgarrado de sua própria cultura, num movimento continuo pelo encontro com outras culturas. Portanto, essa experiência com coronariopatas remeteu a importância do pesquisador com o olhar etnográfico nos estudos concernentes a saúde, pois, é imprescindível considerar as dimensões valorativas das ações e emoções humanas. Estudos assim, apontam pistas e direções para novas reflexões, sobretudo quando se considera que visam justificar propostas de intervenções em ações coletivas inscritas nesse campo.

\section{REFERÊNCIAS}

ADORN0, Rubens Camargo Ferreira.; CASTRO, Ana Lúcia. 0 exercício da sensibilidade: pesquisa qualitativa e a saúde como qualidade. Saúde e Sociedade. v. 3, n. 2, p. 172-85,1994.

BACHELARD, Gaston. A formação do espírito científico: contribuição para uma psicanálise do conhecimento. Rio de Janeiro: Contraponto, 1996.

BEAUD, Stéphane; WEBER, Florence. Guia para a pesquisa de campo: produzir e analisar dados etnográficos. Petrópolis: Vozes, 2014.

BIZERRIL, José. 0 vínculo etnográfico: intersubjetividade e co-autoria na pesquisa qualitativa. Universitas Ciências da Saúde, Brasília: UniCeub, v. 2, n. 2, p. 153-163, 2004.

BOURDIEU, PIERRE. Le bal des célibataires. Paris: Seuil, 1962. 
CICOUREL, Aaron. La sociologie cognitive. 1 ed. Paris, 1972.

COETZEE, J. M. The Lives of Animals. Nova York: Princeton University Press, 1999.

CRAPANZANO, Vincent. Waiting. The Whites of South Africa. Nova York: Randon House, 1985.

DA MATTA, Roberto. Carnavais, malandros e heróis. Rio de Janeiro, Zahar. 1981.

DALMOLIN, Bernadete Mari; LOPES, Stella Maris Brum; VASCONCELLOS, Maria da Penha Costa. A construção metodológica do campo: etnografia, criatividade e sensibilidade na investigação. Saúde e Sociedade, v. 11, n. 2, p. 19-34, 2002.

ECKERT, Cornelia; ROCHA, Ana Luiza Carvalho. Etnografa: saberes e práticas. Iluminuras, v. 9, n. 21, 2008.

FAVRET-SAADA, Jeanne. Ser afetado. Cadernos de Campo, n.13, p.155-161, 2005.

FOOTE-WHYTE, William. Sociedade de esquina: A estrutura social de uma área urbana pobre e degradada. Rio de Janeiro, Jorge Zahar, 2005.

GEERTZ, Clifford. A interpretação das culturas. Rio de Janeiro: Editora Guanabara Koogan, 1989.

GOLDMAN, Marcio. "Os tambores dos mortos e os tambores dos vivos: etnografia, antropologia e política em Ilhéus, Bahia”. Revista de Antropologia, v. 46, n. 42, p. 445-476, 2003.

GOFFMAN, Erving. Encontros: dois estudos na sociologia da interação. Indianapolis: Bobbs - Merrill, 1961.

GOMES, Mara Andrea; SILVEIRA, Cássio. Sobre uso de métodos qualitativos em Saúde Coletiva, ou a falta que faz uma teoria. Revista de Saúde Pública. v. 46, n. 1, p. 160-165, 2012.

GUBER, Rosana. La etnoggrafia, método, campo y reflexividade. Buenos Aires, Siglo Veintuno. Editores, 2011.

KNAUTH, Daniela Riva; LEAL, Andréa Fachel. A expansão das Ciências Sociais na Saúde Coletiva: usos e abusos da pesquisa qualitativa. Interface, v. 18, n. 50, p. 457-467, 2014.

KOURY, Mauro Guilherme Pinheiro. Pertencimento, medos corriqueiros e redes de solidariedade. Sociologias, v.25, n.12, p.286-311, 2010.

LAPLANTINE, François. Antropologia da saúde. São Paulo: Martins Fontes, 2004.

LÉVI-STRAUSS, Claude. Tristes Trópicos. Lisboa: Edições 70, 1979.

MAGNANI, José Guilherme Cantor. De perto e de dentro: notas para uma etnografia urbana. Revista Brasileira de Ciências Sociais, v. 17, n. 49, p. 11-29, 2002.

MAGNANI, José Guilherme Cantor. Etnografia como prática e experiência. Horizontes antropológicos, v. 15, n. 32, p. 129-156, 2009. 
MALINOWSKI, Bronislaw. Uma teoria científica da cultura: Argonautas do Pacífico Ocidental. São Paulo: Abril Cultural, 1978.

MINAYO, Maria Cecília Souza. 0 desafio do conhecimento: pesquisa qualitativa em saúde. São Paulo, 2010.

SPRADLEY, J. P. The ethnographic interview. New York: Holt, Rinehart and Winston, 1979.

PEIRANO, Mariza. A favor da etnografia. Rio de Janeiro. Relume-Dumará, 1995.

PEIRANO, Mariza. Etnografia não é método. Horizontes Antropológicos, v. 20, p. 377-391, 2014.

POUPART, Jean. A entrevista de tipo qualitativo: considerações epistemológicas, teóricas e metodológicas. In: POUPART, J. et al. (Org.). A pesquisa qualitativa: enfoques epistemológicos e metodológicos. Petrópolis: Vozes, 2012.

VICTORIA, Ceres Gomes; KNAUTH, Daniela Riva; HASSEN, Maria de Nazareth Agra. Pesquisa qualitativa em saúde: uma introdução ao tema. Porto Alegre: Tomo Editorial, 2000. 